\title{
Research on the Innovation of College English Teaching Method in the New Media Era
}

\author{
Li Aihong \\ School of Foreign Studies, Xi'an University of Arts and Science, 710065
}

Keywords: New Media; College English Teaching; Innovation

\begin{abstract}
With the development of network and information technology, the new media era has come. New media technologies have an increasingly profound impact on our work and learning. English is a very practical curriculum, but traditional college English teaching has largely ignored this fundamental attribute of English. The popularization of new media technologies has brought great opportunities for the innovation of college English teaching methods. How to make full use of new media technology and realize the reform and innovative development of college English teaching methods is a realistic problem that needs to be solved in every college English educator.
\end{abstract}

\section{Introduction}

English is a very practical subject. With the continuous development of economy and society, the demand for professional English talents in China has been increasing year by year. However, there is still a great deal of contradiction between the demand for economic and social development and the talent cultivation ability and talent training quality of universities in China. After years of development, the English teaching in universities in our country has achieved notable achievements in many aspects. This is obvious to all. However, we cannot turn a blind eye to the problems existing in college English teaching. On the contrary, we should have a fresh understanding of the deficiencies in education and teaching. Only in this way can we improve the level of English teaching in universities as a whole and further optimize the cultivation and output mechanism of talents in China.

New media is both an environment and a technology. New media is the result of highly developed network and information technology. New media technologies have been unknowingly affecting our lives in many areas. New media technologies can transform dull information into flexible and lively multimedia, allowing people who have access to such information to make a qualitative leap in sensory and cognitive performance.

The continuous maturity and wide application of new media technologies have provided many channels for the innovation of college English teaching methods. How to seamlessly integrate new media technology with college English teaching, and subvert the traditional education and teaching model has become an important support and breakthrough in college English teaching reform in the new era.

\section{The Drawbacks in Traditional College English Teaching}

The disadvantages of traditional English teaching mainly exist in education and teaching mechanism, methods, content setting, evaluation system and so on. The traditional college English teaching takes the classroom as the main position of education and teaching, and the teaching process has almost no extension. Under this education and teaching mechanism, the classroom has basically become the only place where students can acquire knowledge. In classroom teaching, teachers occupy a dominant position, and one-way knowledge transfer between teachers and students is the most important education and teaching method. Although over the years, with the application of slides, multimedia and other techniques, the content of classroom teaching has been enriched and changed, but it still follows the traditional routine. It is difficult for teachers and students to achieve timely interaction of information in class teaching, and many students can only leave the problem after class. Because of the limited time in the classroom, teachers must not only 
take care of the progress of the teaching, but also answer the students with certain questions. The contradiction between teaching and learning is more prominent. In terms of teaching content, due to the limitation of teaching time and conditions, many teachers cannot explain the knowledge points or related cultural connotations. Students can only fully follow the teacher's thinking in teaching. When they encounter content or knowledge points that they are interested in, they cannot effectively expand. Many times just pass by, which has greatly dampened students' interest and enthusiasm for learning. One of the reasons why traditional college English teaching pays more attention to the instillation of theoretical knowledge is that the assessment of theoretical knowledge can be uniform, easy to operate, and the assessment mechanism is relatively easy to establish and follow. In contrast, the assessment of practical ability is much more complex. The assessment of practical skills requires complex standards and more scientific systems. Although many universities and colleges have made some attempts and efforts, they have had little success. This is not only closely related to the background of the original exam-oriented education, but also inseparable with the corresponding technical conditions and technical means.

\section{The Main Features of New Media Technologies}

If we are to reform the teaching methods of college English in the era of new media, we should understand some features of new media technologies. First of all, new media technology has broken through the limitation of traditional media technology in information dissemination and performance. The new media technology is novel in form and vivid in image. The new media technology integrates many elements such as sound, video, and text, and presents them in different ways. The information displayed by the new media technology is flexible and lively. Secondly, the storage of information under the new media has been greatly enhanced. New media technologies can be organically integrated with massive amounts of stored information, and information acquisition and search can be conducted efficiently and conveniently. Finally, the new media technology has a very strong interactivity. Under the new media technology, information is no longer only passively displayed, but can realize real-time communication and interaction between both parties of information transmission. Introducing new media technology into college English teaching can effectively improve the interest of college English teaching. The majority of teachers can break through the limitations of time and space, change traditional teaching methods, and turn boring knowledge into vivid teaching demonstrations. Many features of new media technology can strengthen the flexibility of college English teaching, and even change the technical bottleneck of traditional evaluation methods to make college English teaching at a new stage of development.

\section{The Innovation of College English Teaching Method in the New Media Era}

In the era of new media, the innovation of college English teaching methods should focus on the following aspects.

Change the Traditional Education and Teaching Concept. The reason why the change of philosophy was put in the first place was because of the long-standing gap between our college English teaching philosophy and foreign counterparts. Although new media technologies have many advantages, they ultimately require people's control and design. Therefore, if we do not touch the deep level of ideas, it is difficult to integrate this technology with the needs of education and teaching. We must change the traditional ideas of education and teaching, keep up with the pace of the times, be good at innovation, bold reforms, and forge ahead. We will apply advanced teaching ideas to college English teaching reforms, and use advanced educational concepts to guide the innovation of college English teaching methods. In recent years, many scholars and educators have carried out effective explorations and attempts in theories and practices on how to change the traditional concept of education and teaching, and have achieved good results.

Using New Media Technology to Break Conventional Teaching Model. In the traditional teaching model, teachers are the masters of the classroom. They deliver knowledge and information to students in a limited time by mechanical teaching methods. Although this model is widely 
criticized, it has been used. This mode of teaching make students gradually lose their autonomy and cannot effectively improve their comprehensive ability and quality. New media technologies have effectively extended teaching and learning in time and space. In recent years, micro-curriculum has developed into an important aid to college English teaching under the new media technology. Micro lesson is a tiny course designed for a certain teaching content. It often uses video as the main carrier. Micro lessons record the wonderful teaching process that teachers perform around a certain knowledge point inside and outside the classroom. The duration of micro-curricula is generally short, often within ten minutes. This is indeed a short period of time compared to the forty-five minutes of the traditional class. However, micro-classes are not small and they play an extremely important role in the teaching of new media. With the popularization of network technology, especially the construction of the campus network, the network is no longer a bottleneck restricting information exchange between teachers and students. The popularity of the campus network has provided a good environment for the dissemination of micro-curriculums. The development and use of micro-curriculum enables the majority of students to collect and learn curriculum-related knowledge and information anywhere on the computer and mobile phone, which has become the core of many college education and teaching reform. The introduction of micro-curriculum fully mobilized the students' enthusiasm and initiative. It will change the teacher-led teaching model into a learning model for student autonomy. Students can find insufficiencies in micro-learning, sum up and improve, and even many students participate in the production of micro-curriculum. Through self-learning and thinking independently, students not only strengthens their theoretical knowledge, but also enhances their practical ability. Studies abroad have shown that students' effective learning time in the classroom is often concentrated in the first 20 minutes of the class. After that, students will reduce their learning effects and attention to varying degrees. The popularization of micro lessons fully compensates for the weaknesses of classroom teaching and overcomes the constraints of classroom teaching. In recent years, there have been a handful of cases in which university English teaching has been introduced in flipping classes, and all have achieved good teaching results. Flipping classroom is another successful case of combining new media with college English teaching. There are similarities and differences between flipping classroom and microteaching. The design of flipping classroom is student-centered, using multimedia and other information technologies to drive students' initiative and awareness of learning. The flipping classroom also fully considers students' different levels of learning. In the learning process, interactions between teachers and students, interactions among students, and learning group collaborations are used to distribute the roles that the majority of English teachers play in the original classroom to various learning terminals, and give students the initiative in learning. Since 2012, the practice and application of flipping classrooms have been continuously deepened, and the teaching results obtained have also been fully affirmed by the Ministry of Education. China's Ministry of Education has integrated the development of information technology and education in its 10-year development plan as the direction and focus of education and teaching reform.

Using New Media Technology to Integrate Educational Teaching Resources. New media technology relies on network and information technology to realize long-distance transmission and resource sharing of information. The college English teaching relied on new media technology must fully and scientifically integrate relevant educational and teaching resources. The majority of teachers should fully explore and sort out various educational and teaching resources. At the same time, resources should be regularly updated. The majority of teachers should fully encourage students to participate in the integration of English education and teaching resources, allow students to find learning materials that they are interested in, and let students personally create multimedia resources that help them to learn. Fully tap into students' potential in the interaction between teaching and learning.

Using New Media Technology to Create a New English Learning Environment. The application of new media technologies has made it possible to create a new English learning environment. Due to cultural differences between China and the West, college students are particularly vulnerable to the interference of the native language environment in English learning. 
Therefore, how to create an authentic English learning environment plays an important role in improving the English ability of college students. Due to the limitations of time and conditions in regular English classes, teachers cannot present information such as history, culture, and human geography of English-speaking countries. There is not much time for students to practice such skills as speaking, which has caused many students high scores and low ability. The use of new media technologies through technological means can create an authentic language learning environment for students. Sound and images are the two most widely used methods of information transmission in new media technologies. For example, in the new media environment, English movie broadcasting can convey and show western countries' history, culture, customs, and ideas to students through the very common carrier film. Different from the traditional mode of movie play, under the new media, students can also browse through the various terminals to the film story profile, figure characters and other information. In addition, network resources such as the English song library, distance education system, and campus network classroom under the new media can provide students with an excellent English learning environment.

\section{Conclusion}

With the progress of society and the changes of the times, our requirements for personnel training goals are getting higher and higher. As an important part of the university's basic curriculum, college English occupies a very important position in the entire high-level talent cultivation system. The traditional college English teaching model can no longer meet the demands of talents in social development and progress. How to improve students' comprehensive language application ability to let students truly translate what they have learned into use is a major issue that we need to solve in education and teaching. The advent of the new media era has provided a very broad platform for college English teaching innovation. The new media constantly enriches and influences all areas of our work, study, and life at an unstoppable speed. As college English educators, how to seize the opportunities brought by new media, give full play to its role in college English education and teaching, and effectively promote the sustainable development of college English teaching becomes increasingly urgent and important.

\section{Reference}

[1] H. Z. Hu and L. Zhang. Using the New Media to Improve the Experimental Research of PBL in College English Teaching [J]. Journal of Shijiazhuang University, 2016, 18(1): 131-135.

[2] T. T. Cui and S. B. Liu. Exploration of Practical English Teaching for Postgraduates Based on New Media Support [J]. China Electro-Technical Education, 2015, (6): 122-126.

[3] T. S. Hu. "Micro-curriculum": New Trends in the Development of Regional Education Information Resources [J]. Research on Audio-visual Education, 2011(10).

[4] N. Miao. Research on Mobile Learning Strategies of College English Based on WeChat [J]. China Electro-Technical Education, 2016(3): 136-137.

[5] P. Hu and R. K. Chen. On the Application of New Media Technology in College English Teaching [J]. Journal of Changzhou Normal University, 2016, 32(2): 127-129.

[6] Yu D, Peng L. When does Inferring Reputation Probability Countervail Temptation in Cooperative Behaviors for the Prisoners' Dilemma Game? [J]. Chaos, Solitons \& Fractals, 2015, 78: $238-244$. 